\title{
Severe dystonia as the first manifestation of neuromyelitis optica
}

Distonia grave como primeira manifestação de neuromielite óptica

Yára Dadalti Fragoso ${ }^{1,2}$, Joseph Bruno Bidin Brooks ${ }^{1,2}$, Celso Luis Silva Oliveira ${ }^{2}$

1Department of Neurology, Universidade Metropolitana de Santos, Santos SP, Brazil;

${ }^{2}$ Multiple Sclerosis Reference Center for the Coastal Region of the State of São Paulo, Santos SP, Brazil.

Correspondence: Yara Dadalti Fragoso; Departamento de Neurologia, Universidade Metropolitana de Santos; Rua da Constituição 374; 11015 -470 Santos SP - Brasil; E-mail:yara@bsnet.com.br

Conflict of interest: There is no conflict of interest to declare.

Received 07 April 2012; Received in final form 20 April 2012; Accepted 27 April 2012

Dear Editors,

We read the recent and interesting paper written by Schmidt et al. ${ }^{1}$, reporting on four patients with paroxysmal dystonia secondary to spinal lesions during the recovering phase of a neuromyelitis optica (NMO) relapse. Indeed, generalized movement disorders may be a manifestation of lesions in several regions of the central nervous system, and the cervical spinal cord is one of these. We would like to present to such discussion a case of NMO that started with severe dystonia.

A 40-year-old female patient presented an eight-month history of progressive movement disorder described by her as cramps in both her feet, which rapidly rendered her unable to walk. Within a month, her hands were also affected. Her feet and hands were in extreme flexion, very painful, and made worse by startling noises. The episodes occurred every two or three minutes and lasted about one minute. Within two months, there were almost no free intervals, and even during her sleep she continued to present the painful and abnormal posture of the extremities. She then started to present uncontrollable hiccups and profuse sweating, and she was completely dependent on a caregiver. Even the slightest touch on her body would worsen the pain and posture. She was seen by several neurologists. Her brain magnetic resonance imaging (MRI) was normal and her spinal cord MRI showed an extensive lesion in the cervical region (Figure). Her cerebrospinal fluid (CSF) analysis showed 42 lymphomonocytes and total protein of $55 \mathrm{mg} / \mathrm{dL}$, while the remainder of the evaluation was unremarkable. Serum antiaquaporine-4 was positive 1:160. Benzodiazepines, corticosteroids, acetazolamide,
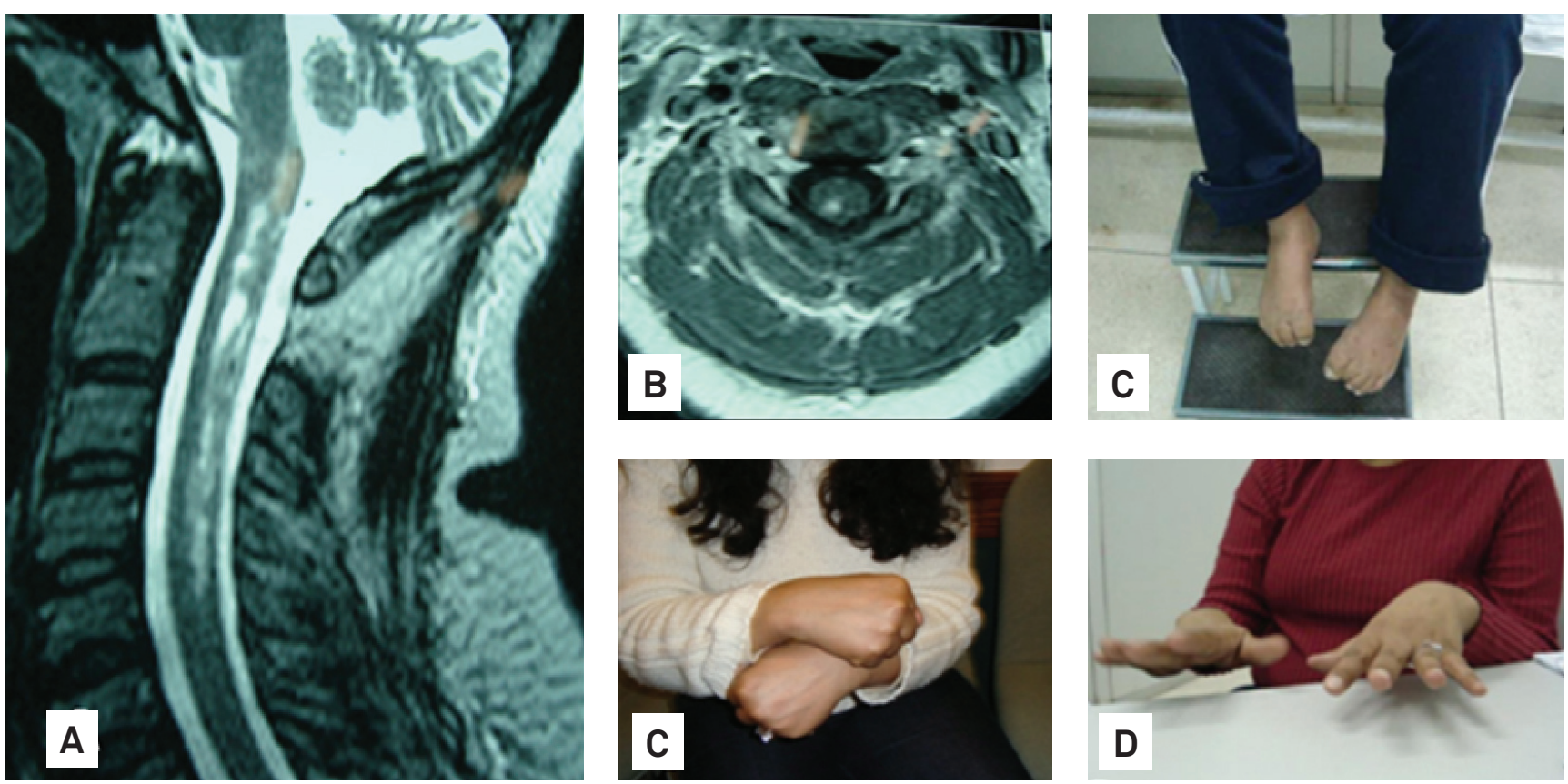

Figure. (A and B) Cervical spinal cord magnetic resonance imaging. (C) Hands and feet at initial consultation. (D) Hands after oneweek treatment with carbamazepine from 200 (three days) to 400 mg/day (four days). 
levodopa, hydantoin, baclofen, valproate, gabapentin, and neuroleptics were prescribed to her, all of them in progressively increasing doses. These drugs were used singly and in association, all to no or minimal avail.

Her neurological examination showed muscle strength IV in all limbs, however every attempt to assess her strength led to worsening of the athetosis-dystonia. Her gait and coordination could not be assessed, since she was severely disabled by the involuntary movements and abnormal posture. There was predominance of flexion and abduction of the arms and legs, which were more pronounced in the fingers and toes (Figure). Sensitivity was normal, as were the cranial nerves.

She was prescribed carbamazepine $200 \mathrm{mg} /$ day, with increasing doses up to $600 \mathrm{mg} /$ day within two weeks. Her response was dramatic, and she returned for a new assessment within a week. Although still presenting a degree of dystonia in all four limbs, she could walk unaided and use her both hands for daily activities.

Bilateral optical neuritis was developed nine months later. She continued her treatment with carbamazepine, azathioprine, and corticosteroid pulses when required. Three years and four relapses later the patient presents severe visual and motor disability.

We believe that this patient spent eight months without proper diagnosis due to the difficulties encountered by all the neurologists involved in her case. As very properly pointed out by Schmidt et al. ${ }^{1}$, the literature is scarce on NMO bouts manifesting as athetosis-dystonia.

\section{References}

1. Schmidt FR, Costa FHR, Silva FMLC, et al. Paroxysmal dystonia and neuromyelitis optica. Arq Neuopsquiatr 2012;70:271-272. 